\title{
The effect of oil price changes on the price of Russian and Chinese oil shares
}

\author{
Stephen G. Hall ${ }^{1}$ • Amangeldi Kenjegaliev ${ }^{2}$
}

Received: 18 September 2014 / Accepted: 13 August 2016 / Published online: 4 October 2016 C The Author(s) 2016. This article is published with open access at Springerlink.com

\begin{abstract}
Do changes in oil prices have an effect on stocks of oil companies in emerging markets? Do the shares of oil companies in emerging markets react to the price news in a similar way as those of the Western companies? This paper aims to answer these questions utilizing event study techniques. As expected, the results of both parametric and nonparametric tests suggest that the fluctuations in oil prices have an effect on the stock prices. However, an interesting result is that the responses of stocks of Chinese and Russian oil companies are considerably different from the shares of their Western counterparts.
\end{abstract}

Keywords Event studies - Abnormal return - Parametric $t$ test · Nonparametric rank test · Oil companies

JEL Classification G-14 · Q-49

\section{Introduction}

Do changes in oil prices have an effect on the stocks of major emerging economy oil companies? The answer to this question seems rather obvious. Yes, there must be a connection between the oil price changes and stock returns of oil companies' shares.

We are grateful to Heather Anderson (Editor) and two anonymous referees for valuable comments and suggestions. We also thank Scott McCracken for his feedback on the paper.

Amangeldi Kenjegaliev

a.kenjegaliev@hull.ac.uk

1 Department of Economics, University of Leicester, University Road, Leicester LE1 7RH, UK

2 Hull University Business School, Cottingham Road, Hull HU6 7RX, UK 
However, do the shares of oil companies of emerging markets react to the price news in a similar way to Western companies? This study intends to provide answers to both questions, with particular emphasis on the latter, utilizing event study methodology.

The event study methodology investigates the impact of news on security prices. Depending on the type of information, announcements increase or decrease the value of a stock on the market. Event study methodology involves estimating the normal return for a security and calculating the direction and size of the excess return attributable to unanticipated information. Econometric techniques used in event studies are provided by Brown and Warner (1980, 1985), Dyckman et al. (1984), Jain (1986), Ball and Taurus (1988), Corrado (1989), Corrado and Zivney (1992), Kritzman (1994), McWilliams and Siegel (1997), Bartholdy et al. (2007), Díaz and Jareno (2013), Liebman and Tomlin (2015) and Kenjegaliev et al. (2016). The theory is still growing, and the number of economists researching in this area is increasing, along with the sophistication of studies.

However, despite this development, to the best of our knowledge, there are no empirical event study investigations on oil companies of Western and emerging markets and oil prices. Our paper aims to fill this gap. The analysis is performed on twelve major oil companies. The companies represent the four key markets: well-established Western economies such as the USA and Europe, and emerging economies such as Russia and China.

The remainder of this article is organized as follows. Section 2 presents the derivation of abnormal returns and cumulative abnormal returns. In this section, two tests are presented: the parametric $t$ test and the nonparametric rank test. The results of these tests and a discussion are given in Sect. 3. In Sect. 4 we present supplementary analysis. Finally, Sect. 5 concludes.

\section{Theoretical background}

There are a large number of models that can be used to investigate event studies. These models consist of identifying the event and testing for excess profit. Tests are constructed in such a way that they detect abnormal performance. There are two broad approaches in conducting the tests: parametric and nonparametric. The former approach is usually based on a standard $t$ test. In the case of event studies, standard $t$ tests check whether the residuals are statistically different from the normal student $t$-distribution. The numerator of the $t$ test represents the abnormal return for a particular date, while the denominator scales the top part by the level of dispersion or the standard deviation of a given time series. The parametric test used in this paper is based on a traditional $t$ test (Brown and Warner 1980, 1985). This test is conducted for cumulative abnormal return (MacKinlay 1997) of individual companies. In addition, a hypothetical portfolio consisting of oil companies is extensively analysed.

The parametric test deals directly with the residuals. However, the nonparametric test has a different approach to detect abnormal performances. For example, the nonparametric sign test, unlike the standard $t$ test, does not check the abnormal returns but the respective signs of their residuals. The probabilities of negative and positive signs in this test are assumed to be equal. Another approach to testing the presence or 


\section{(Estimation window] (Event window] (Post-event window]}

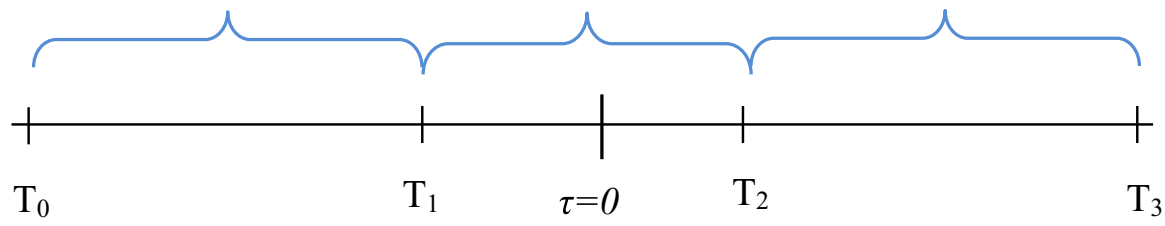

Fig. 1 Time line for estimation period (MacKinlay 1997, p. 20)

lack thereof of abnormal performances of stocks is the nonparametric rank test. This test ranks the residuals in the time series and tests the rank of the return for abnormal performance. In the paper, in addition to traditional test, we employ nonparametric rank test.

To measure the abnormal return, we use two statistical models. These are the constant mean model and the market model. Despite their relative simplicity, these models can be effectively used in the event study methodology. These two models are presented below. The first model is the constant mean model:

$$
\begin{aligned}
& R_{i t}=\mu_{i}+\varepsilon_{i t} \\
& E\left(\varepsilon_{i t}\right)=0 \text { and } \operatorname{Var}\left(\varepsilon_{i t}\right)=\sigma_{\varepsilon_{i}}^{2}
\end{aligned}
$$

where $R_{i t}$ represents the returns of security $i$ at time $t, \mu_{i}$ is the mean return for security $i$, and $\varepsilon_{i t}$ is the error term for security $i$ at time $t$ with mean equal to zero and variance, $\operatorname{Var}\left(\varepsilon_{i t}\right)=\sigma_{\varepsilon_{i}}^{2}$.

The second model utilized in this article is that of the market model. This model is a statistical model relating security returns to market movements and is popular due to its ability to capture market movement in security returns.

$$
\begin{aligned}
& R_{i t}=\beta_{i}+\psi_{i} R_{m t}+e_{i t} \\
& E\left(e_{i t}\right)=0 \text { and } \operatorname{Var}\left(e_{i t}\right)=\sigma_{e_{i}}^{2}
\end{aligned}
$$

where $R_{i t}$ and $R_{m t}$ are security and market returns at time $t$, respectively; $\beta_{i}$ and $\psi_{i}$ are the coefficients of the market model. Following MacKinlay (1997), as a proxy for the market return, we use the Standard \& Poor's Index.

To detect the abnormal return, you need to define the event time, $\tau$ (see Fig. 1). ${ }^{1}$ We define the event date as an oil price change at $\tau=0$, the estimation window is from $\tau=T_{0}+1$ to $\tau=T_{1}$, and the event window is from $\tau=T_{1}+1$ to $\tau=T_{2}$. The lengths of the estimation window and the event window are: $L_{1}=T_{1}-T_{0}$ and $L_{2}=T_{2}-T_{1}$, respectively. The post-event window is $\tau=T_{2}+1$ to $\tau=T_{3}$. The length of the post-event window is $L_{3}=T_{3}-T_{2}$.

\footnotetext{
1 The derivation of an estimation period i.e. estimation window, the event window and the post-event window, is taken from MacKinlay (1997, p. 19).
} 
To compute the abnormal return of the constant mean model, we use the following equation

$$
\mathrm{AR}_{i \tau}=R_{i \tau}-\hat{\mu}_{i}
$$

where $\mathrm{AR}_{i \tau}$ is the abnormal return of the $i$ th security at time $t, R_{i \tau}$ is the return of the $i$ th security in event period $\tau$, and $\hat{\mu}_{i}$ is the estimated mean return of the analysed security.

The estimation of the parameters of the market model for the $i$ th firm at the event time involves identifying the $\beta, \psi$ and variance of the market model. Using the estimated parameters, $\hat{\beta}$ and $\hat{\psi}$, obtained by ordinary least squares from the market model, it is possible to compute the abnormal return. Residuals represent excess returns. The expected return according to Bartholdy et al. (2007) is given by the following equation

$$
E\left(R_{i \tau}\right)=\hat{\mu}_{i \tau}=\hat{\beta}_{i}+\hat{\psi}_{i} R_{m \tau}
$$

The discrepancy between the actual return and the expected return, adjusted for market movements over the analysed period, is the abnormal return (see Eq. 5).

$$
\mathrm{AR}_{i \tau}=R_{i \tau}-\hat{\beta}_{i}-\hat{\psi}_{i} R_{m \tau}
$$

In the constant mean model and the market model, the test statistic relies on the assumption of a normal distribution for returns. Under the null hypothesis, the distribution of the abnormal returns is given by:

$$
\mathrm{AR}_{i \tau} \sim N\left(0, \sigma^{2}\left(\mathrm{AR}_{i \tau}\right)\right)
$$

where the mean of the abnormal return is jointly normally distributed with a zero mean and variance, $\sigma^{2}\left(\mathrm{AR}_{i \tau}\right)$. The null hypothesis tests that the event does not have an impact on the abnormal return.

To detect that the event has an impact on the abnormal performance of the securities portfolio, the excess returns of securities have to be aggregated. Aggregation for abnormal returns of the securities can be made through securities and then through time. In this paper, the aggregation is made across the securities at the same event dates. By doing this, you obtain the average abnormal return across securities over $n$ events. This aggregation is given by:

$$
\overline{\mathrm{AR}}_{\tau}=\frac{1}{n} \sum_{j=1}^{n} \mathrm{AR}_{j \tau}
$$

And the variance of the aggregated abnormal returns is:

$$
\operatorname{Var}\left(\overline{\mathrm{AR}}_{\tau}\right)=\frac{1}{n^{2}} \sum_{j=1}^{n} \sigma_{\varepsilon_{j}}^{2}
$$

After calculating the abnormal return for the securities, you can aggregate it over the event window to find the overall impact of the event. Cumulating the abnormal returns through the event window is necessary to detect the excess returns. 
The cumulative abnormal return (CAR) is the sum of the aggregated abnormal returns. In order to find the CAR, we use the following equation:

$$
\operatorname{CAR}_{i}\left(\tau_{1}, \tau_{2}\right)=\sum_{\tau=\tau_{1}}^{\tau_{2}} \operatorname{AR}_{i \tau}
$$

where $T_{1}<\tau_{1} \leq \tau_{2} \leq T_{2}$ and $\operatorname{CAR}_{i}\left(\tau_{1}, \tau_{2}\right)$ is the cumulative abnormal returns of security $i$ from $\tau_{1}$ to $\tau_{2}$. The variance of the CAR is:

$$
\sigma_{i}^{2}\left(\tau_{1}, \tau_{2}\right)=\left(\tau_{2}-\tau_{1}+1\right) \sigma_{\varepsilon_{i}}^{2}
$$

It is assumed that the distribution of the cumulative abnormal returns under the null hypothesis is:

$$
\mathrm{CAR}_{i}\left(\tau_{1}, \tau_{2}\right) \sim N\left(0, \sigma_{i}^{2}\left(\tau_{1}, \tau_{2}\right)\right)
$$

The aggregation of cumulative abnormal returns can also be done across securities in a similar way:

$$
\overline{\operatorname{CAR}}\left(\tau_{1}, \tau_{2}\right)=\sum_{\tau=\tau_{1}}^{\tau_{2}} \overline{\operatorname{AR}}_{\tau}
$$

where $\mathrm{AR}_{\tau}$ is the abnormal return in event period $\tau$

The variance for above equation is:

$$
\operatorname{Var}\left(\overline{\operatorname{CAR}}\left(\tau_{1}, \tau_{2}\right)\right)=\sum_{\tau=\tau_{1}}^{\tau_{2}} \operatorname{Var}\left(\overline{\mathrm{AR}}_{\tau}\right)
$$

The cumulative abnormal return for the portfolio of securities is:

$$
\overline{\operatorname{CAR}}\left(\tau_{1}, \tau_{2}\right)=\frac{1}{n} \sum_{i=1}^{n} \overline{\operatorname{AR}}_{i \tau}
$$

and variance is:

$$
\operatorname{Var}\left(\overline{\mathrm{CAR}}\left(\tau_{1}, \tau_{2}\right)\right)=\frac{1}{n^{2}} \sum_{i=1}^{n} \operatorname{Var}\left(\overline{\mathrm{AR}}_{i \tau}\right)
$$

Testing for the significance of the abnormal returns can be performed along two broad avenues: parametric and nonparametric.

The parametric tests rely on the assumption of a normal distribution. Lehman (see in Higgins and Peterson 1998) states that the ordinary $t$ test is optimal when the distribution of the returns is normal. Thus, assuming that the residuals are normally distributed, it is possible to conduct a $t$ test such that under the null hypothesis the test statistic shows no abnormal return, i.e.

$$
\mathfrak{s}_{1}=\frac{\overline{\mathrm{AR}_{i}}}{\sqrt{\operatorname{Var}\left(\overline{\mathrm{AR}_{i}}\right)}}
$$


Table 1 Summary of hypotheses

\begin{tabular}{ll}
\hline$H_{0}: \mu=0$ & $\begin{array}{l}\text { Oil stock returns do not behave differently } \\
\text { after oil price shocks }\end{array}$ \\
& Oil price shocks are associated with \\
& abnormal returns in oil stock prices. \\
& Market does not anticipate, but reacts \\
& directly after the shock
\end{tabular}

where $\overline{\mathrm{AR}_{i}}$ is the average abnormal return during the event date and $\operatorname{Var}\left(\overline{\mathrm{AR}_{i}}\right)$ is the variance of the abnormal return at this date.

Using the cumulative abnormal return and the variance of the cumulative return, you can test the null hypothesis, $H_{0}: \mu=0$ (see Table 1 ).

$$
\Im_{i}^{\mathrm{CAR}}=\frac{\overline{\operatorname{CAR}}\left(\tau_{1}, \tau_{2}\right)}{\sqrt{\operatorname{Var}\left(\overline{\operatorname{CAR}\left(\tau_{1}, \tau_{2}\right)}\right)}} \sim N(0,1)
$$

The hypotheses we test are presented in Table 1.

The primary disadvantage of parametric tests is that they rely on particular distributional assumptions, for example that stock returns are normally distributed. Despite this assumption being widely used in finance and economics, most of the financial data, and in particular daily data, does not follow a normal distribution. For instance, Brooks (1996) investigates nonlinearities in daily exchange rates and finds that financial series display strong signs of departure from normality (see also Hsieh 1988; Baillie and Bollerslev 1989). To remedy this, some authors incorporate a GARCH effect in their research. For example, Jong et al. (1992) note that assumptions of the market model are often violated, particularly with daily data. They find that ignoring fat tails and heteroscedasticity leads to spurious results. In a similar spirit, Corhay and Rad (1996) correct excess returns of the market model using the GARCH effect which leads, according to the authors, to more efficient estimators. They also suggest to use longer financial time series due to the behaviour of the variance, which is a proxy for risk.

On the other hand, to overcome this problems, other studies employ a nonparametric tests which do not depend on the assumption of a normal distribution in the financial series. For example, Brown and Warner (1985), Corrado (1989), Corrado and Zivney (1992), Cowan (1992), Cowan and Sergeant (1996), and Bartholdy et al. (2007) use nonparametric tests in addition to parametric tests.

In this paper, in addition to the ordinary $t$ test, we use the nonparametric rank test specified in Corrado (1989). Corrado (1989) employs a nonparametric rank test for excess performance to test for significance of abnormal returns. This test has similarities with the ordinary $t$ test; however, instead of the abnormal returns, it uses the rank of the abnormal return. For example, consider a sample of observations of abnormal returns in the event window for each of $n$ firms. As we stated above, to apply the nonparametric rank test, you need to rank the abnormal return for each security. The highest rank is given to the highest price of the security and vice versa for the 
lowest rank. Therefore, the rank test transforms the excess returns into a uniform distribution across ranks. Hence, to apply the nonparametric rank test, you should convert the given time series into its respective ranks. Denoting $K_{i \tau}$ as the rank of the excess return, $\mathrm{AR}_{i \tau}$, of the $i$ th firm and with the size of the estimation window $W_{\text {est }}$ days and the event window comprising $W_{\text {event }}$ days, the following holds:

$$
K_{i \tau}=\operatorname{rank}\left(\mathrm{AR}_{i \tau}\right)
$$

The range of $\tau$ in Eq. (18) is

$$
\tau=\alpha-\left(W_{\text {est }}+\frac{W_{\text {event }}-1}{2}\right), \ldots, 0, \ldots,\left(\frac{W_{\text {event }}-1}{2}\right)-\omega
$$

where $\alpha=0,1, \ldots,\left[\left(W_{\text {est }}+\frac{W_{\text {event }}-1}{2}\right)-1\right]$ and $\omega=\left[\left(\frac{W_{\text {event }}-1}{2}\right)-1\right], \ldots, 1,0$; with $\tau<0$ indicating the number of days prior the event, $\tau=0$ - the event day and $\tau>0$ - days after the event.

Corrado (1989) reports that the average rank is one-half plus half the number of observed returns. Thus, the average rank is $1 / 2\left(W_{\text {est }}+W_{\text {event }}\right)$. The test statistic is given by:

$$
\Im_{2}=\frac{1}{n} \sum_{i=1}^{n} \frac{\left[K_{i \tau}-1 / 2\left(W_{\mathrm{est}}+W_{\mathrm{event}}\right)\right]}{S D(K)}
$$

where $\left[K_{i \tau}-1 / 2\left(W_{\text {est }}+W_{\text {event }}\right)\right]$ is a proxy for the abnormal return (Corrado 1989). The standard deviation of the rank test is determined by using a sample period of $\left(W_{\text {est }}+W_{\text {event }}\right)$ days and given in Eq. (20).

$$
\mathrm{SD}(K)=\sqrt{\frac{1}{\left(W_{\mathrm{est}}+W_{\text {event }}\right)} \sum_{\tau=-\left[W_{\text {est }}+\left(W_{\text {event }}-1\right) / 2\right]}^{+\left(W_{\text {event }}-1\right) / 2}\left(\frac{1}{n} \sum_{i=1}^{n}\left[K_{i \tau}-1 / 2\left(W_{\text {est }}+W_{\text {event }}\right)\right]\right)^{2}}
$$

Test of the null hypothesis can be implemented using the result that the asymptotic null distribution is a standard normal. Therefore, the main feature of the rank test consists of ranking each observation in order to bring them into a uniform distribution. The rest of the procedure of the test does not considerably differ from the $t$ test statistics.

\section{Empirical data and results}

Our research focuses on twelve oil companies. These are companies of

- The USA Chevron and Exxon Mobil;

- Western Europe British Petroleum, Eni, Total and Royal Dutch Shell;

- Russia GazProm, LukOil and SurgutNefteGaz; and

- China China Petroleum and Chemicals, Petrochina and Sinopek.

The data for oil stocks are taken from DataStream. The oil prices are represented by crude oil prices (Cushing, OK WTI Spot Price FOB) which are extracted from 


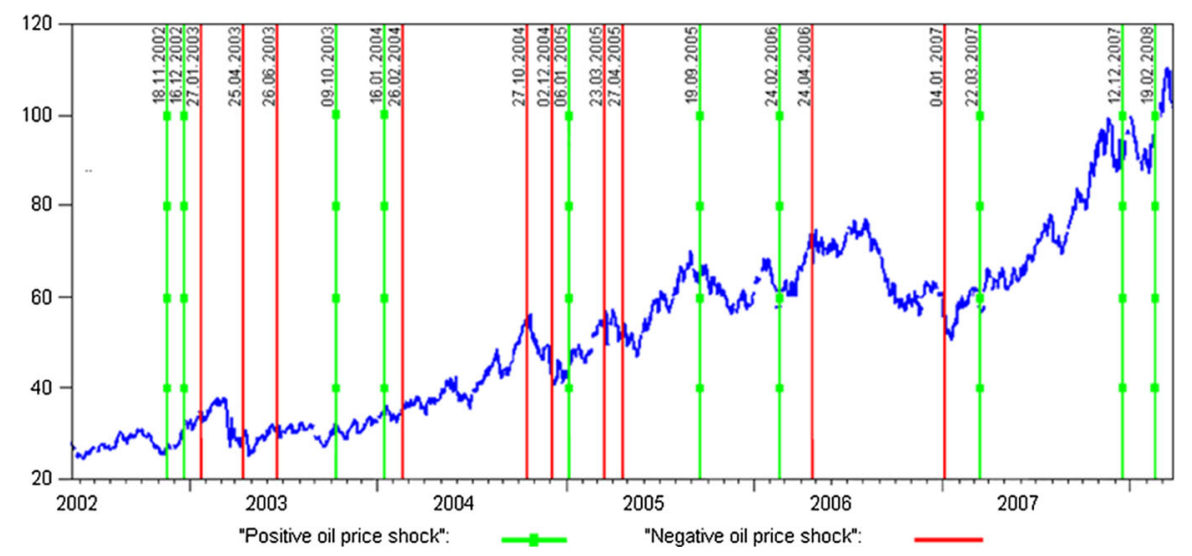

Fig. 2 Plot of crude oil prices with event dates

the Energy Information Administration (http://www.eia.doe.gov). Data are daily time series both for oil prices and oil stocks.

The time series consists of the daily data for the period spanning from the 1 January 2000 to the 18 March 2008. The period after 2008 is excluded due to the sharp fall in oil price in 2008 which is followed by the global financial crisis. The first analysed event date starts in 2002. The events are divided into 2 types of news: "positive oil price shock' and 'negative oil price shock'. 2 The following criterion is used to define the news and its type. If the price of oil on a particular day is greater by $4.5 \%$ than the price the previous day, then the news is classified as a 'positive oil price shock'. If, on the other hand, the day's oil price is less than the previous day's price by $4.5 \%$, then the news is classified as a 'negative oil price shock' (see Fig. 2). We choose $4.5 \%$ change in oil prices to obtain a sufficient number of observations in the sample. ${ }^{3} \mathrm{We}$ also removed some events to insure that there are at least 30 days between each one. This is done to control for any impact of other events on stock prices around the day of the event. In addition, we tried to match news related to the oil industry and released around the event dates (see Table 2).

\subsection{The parametric $t$ test}

According to the $t$ test derived from the constant mean model, on date zero, $\tau=0$, there is no significant abnormal return for the 'positive oil price shock'. The abnormal return for that date is 0.1 and variance is equal to 0.0004 . The value of $\Im_{1}^{\text {CAR }}$ is low, 0.034 . However, at the event date, the sign of the cumulative abnormal return changes from negative to positive. In addition, the value of the test statistics $\Im_{1}^{C A R}$ on the 15 th, 14 th and 13 th days prior to the event are $-3.0,-4.3$ and -3.5 , respectively. The next

\footnotetext{
2 We interchangeably use 'good news' for 'positive oil price shock' and 'bad news' for 'negative oil price shock' throughout the paper.

3 We also tried 5 and $4 \%$ oil price changes. In the former case we had too many events while in the latter we had too few events.
} 
Table 2 News associated with oil price shocks

\begin{tabular}{llll}
\hline $\begin{array}{l}\text { Positive oil price shock } \\
(+4.5 \%)\end{array}$ & News & $\begin{array}{l}\text { Negative oil price } \\
\text { shock }(-4.5 \%)\end{array}$ & News \\
\hline 18.11 .2002 & $\begin{array}{c}\text { Spanish oil spill threat } \\
\text { recedes }\end{array}$ & 27.01 .2003 & \\
16.12 .2002 & $\begin{array}{c}\text { Oil refinery blaze } \\
\text { biggest for years }\end{array}$ & 25.04 .2003 & \\
09.10 .2003 & & 26.06 .2003 & \\
16.01 .2004 & 26.02 .2004 & \\
06.01 .2005 & 27.10 .2004 & $\begin{array}{c}\text { Texas oil plant blast } \\
\text { 'kills 14' }\end{array}$ \\
19.09 .2005 & $\begin{array}{l}02.12 .2004 \\
\text { Judges postpone their } \\
\text { verdict on Mikhail } \\
\text { Oil prices dip despite } \\
\text { storm fear }\end{array}$ & 23.03 .2005 & $\begin{array}{c}\text { Khodorkovsky till } \\
16 \text { May }\end{array}$ \\
22.03 .2007 & $\begin{array}{c}\text { Saudis 'foil oil facility } \\
\text { attack' }\end{array}$ & 27.04 .2005 & \\
& & & $\begin{array}{c}\text { Russia oil row hits } \\
\text { Europe supply }\end{array}$ \\
\hline
\end{tabular}

All news are related to the oil industry. News headlines are taken from BBC. Some news are released after the event. We couldn't identify relevant news in 2003; however on 20th March 2003 the US started the war in Iraq

significant negative abnormal return is a week before the event date with $\Im_{1}^{\text {CAR }}$ equal to -2.7 for that date.

For the case of the 'negative oil price shock', the $t$ test does not show significance of the abnormal return. Despite this, 1 day before the event the abnormal return was 0.13 while at the event date the level of cumulative abnormal return fell to 0.04 . The $\Im_{1}^{\mathrm{CAR}}$ for the day before the event is 1.72 . A statistically significant abnormal return is observed from dates -18 and -1 with statistical significance ranging from 0.5 to $5 \%$. The highest level of cumulative abnormal return is observed on the 14th day before the event with $\Im_{1}^{\mathrm{CAR}}$ being equal to 3.6.

After the event date, the paths of the cumulative abnormal returns for the 'negative oil price shock' and the 'positive oil price shock' are similar.

From Figs. 3 and 4, you can observe that the market model results are not significantly different from those of the constant mean model. These figures also show the high level of abnormal return on the 14th day prior the event for the 'negative oil price shock'. There are some dissimilarity in the cumulative abnormal returns for the constant mean model compared to the market model. However, it can possibly be attributed to the market movement. In other words, the divergence is potentially caused by the changes in market preferences of investors after the sharp increase or decrease in oil prices. 


\section{Constant Mean Model}

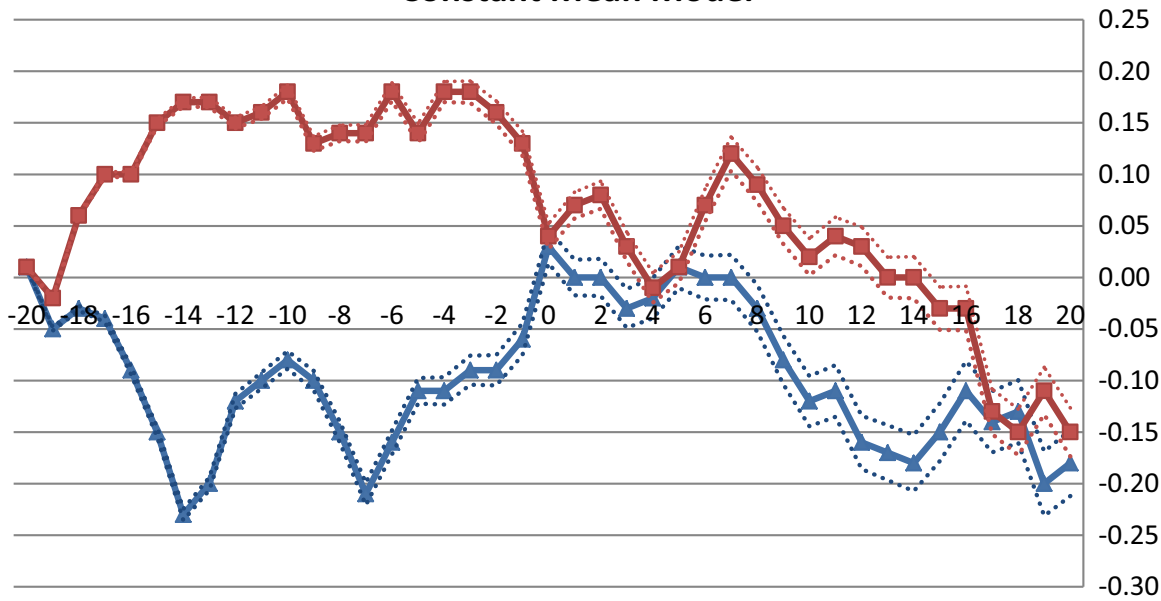

Fig. 3 Plot of cumulative abnormal returns for the constant mean model averaged for 12 companies. The horizontal axis represents the event window, with date 0 as the event time. The vertical axis represents the cumulative abnormal returns for this period. The dotted lines show $95 \%$ confidence intervals using standard errors averaged across events and companies

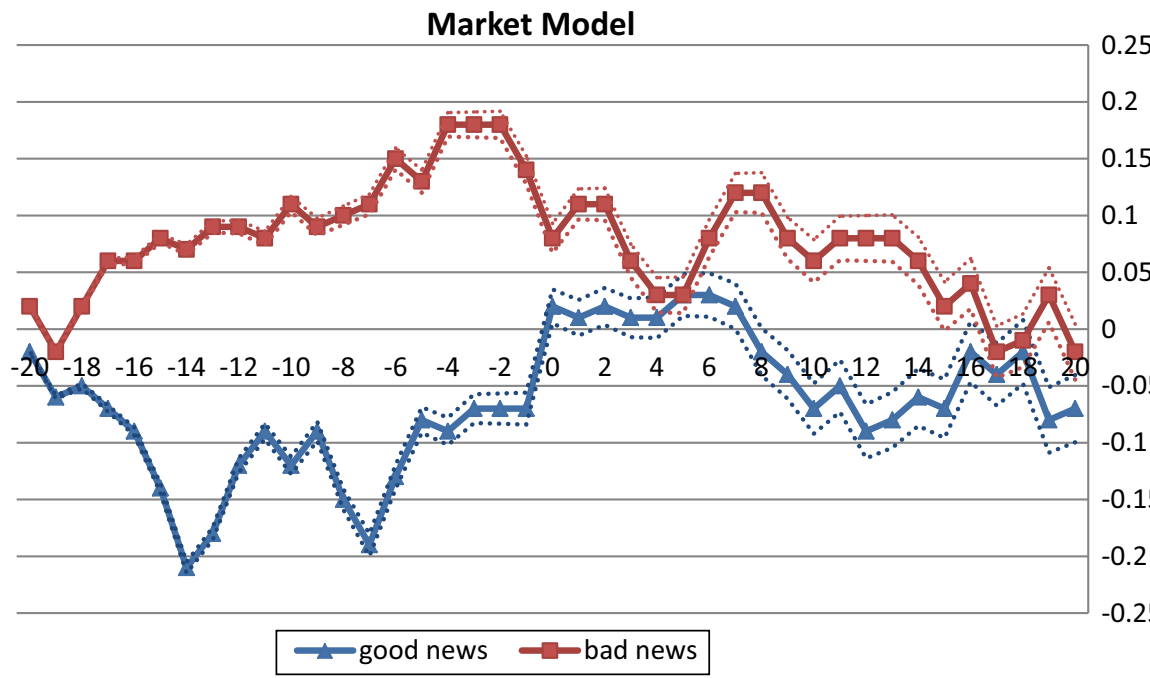

Fig. 4 Plot of cumulative abnormal returns for the market model averaged for 12 companies. The horizontal axis represents the event window, with date 0 as the event time. The vertical axis represents the cumulative abnormal returns for this period. The dotted lines show $95 \%$ confidence intervals using standard errors averaged across events and companies

For individual companies, computed from the constant mean model, the $t$ test indicates insignificant CAR at the event date. The $t$-statistic is high for the 15 th, 14 th and 13th days prior to the event compared to those of the other dates. The highest, 

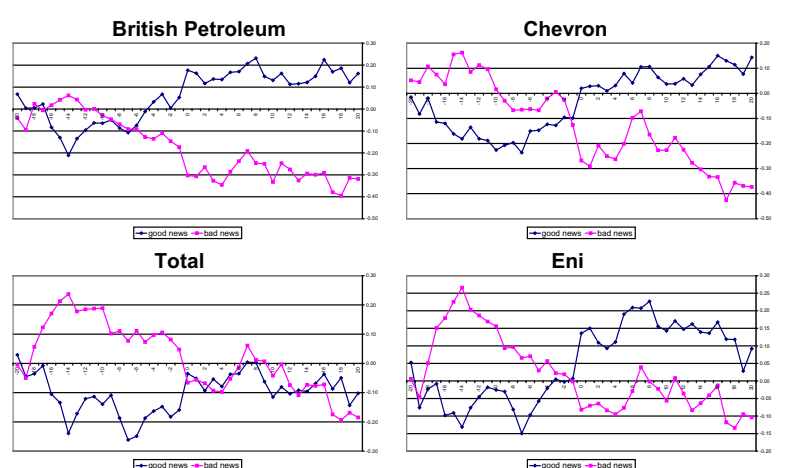

Eni

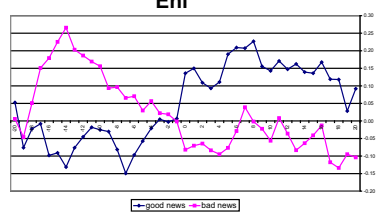

$\rightarrow$ good news $-\rightarrow$-bad news

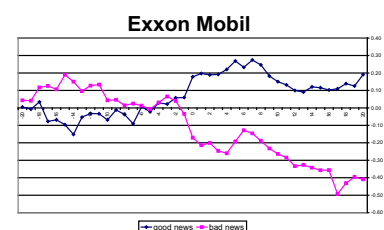

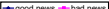

Royal Dutch Shell

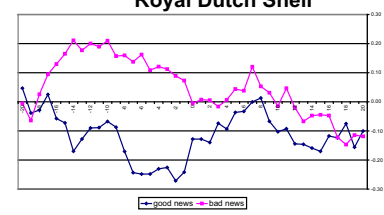

Fig. 5 Plot of cumulative abnormal returns for the constant mean model for six Western companies. The horizontal axis represents the event window, with date 0 as the event time. The vertical axis represents the cumulative abnormal returns for this period

Lukoil

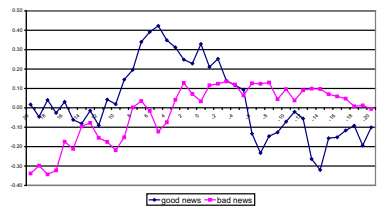

Sinopec

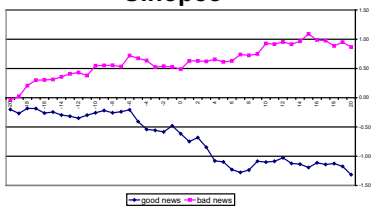

Gazprom

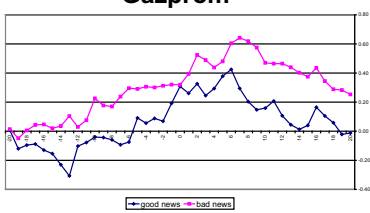

Petrochina

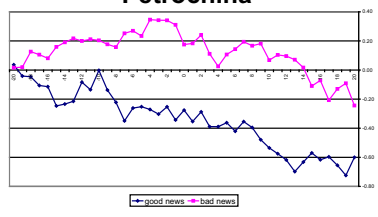

Surgutneftegaz

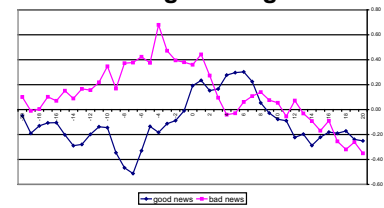

China Petroleum and chemicals

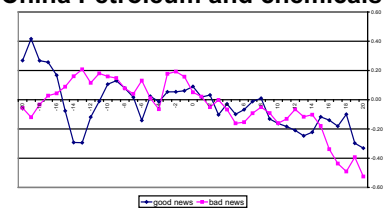

Fig. 6 Plot of cumulative abnormal returns for the constant mean model for three Chinese and three Russian companies. The horizontal axis represents the event window, with date 0 as the event time. The vertical axis represents the cumulative abnormal returns for this period

but still insignificant, value of the $t$-statistic is observed at the date -14 . The sign of the cumulative abnormal return for the most of the Western companies is negative before the event. However, after the event the cumulative abnormal return changes to positive. Exceptions are Total and Royal Dutch Shell. The abnormal returns for securities of these two companies have negative signs throughout the event period (see Fig. 5).

The $t$-statistic calculated from the market model at the event date is lower than the $t$-statistic computed by the constant mean model. The signs of the cumulative abnormal returns are roughly similar to the ones obtained by the constant mean model with sporadic negative signs after the event date (Fig. 6).

For the case of the 'negative oil price shock', the $t$ test does not show significance of the abnormal return after the event. The $t$ test indicates statistically significant positive abnormal returns for Total, Eni and Royal Dutch Shell's stocks 2 weeks before the event. Nevertheless, at this day the market model does not report significant 


\section{Constant Mean Model}

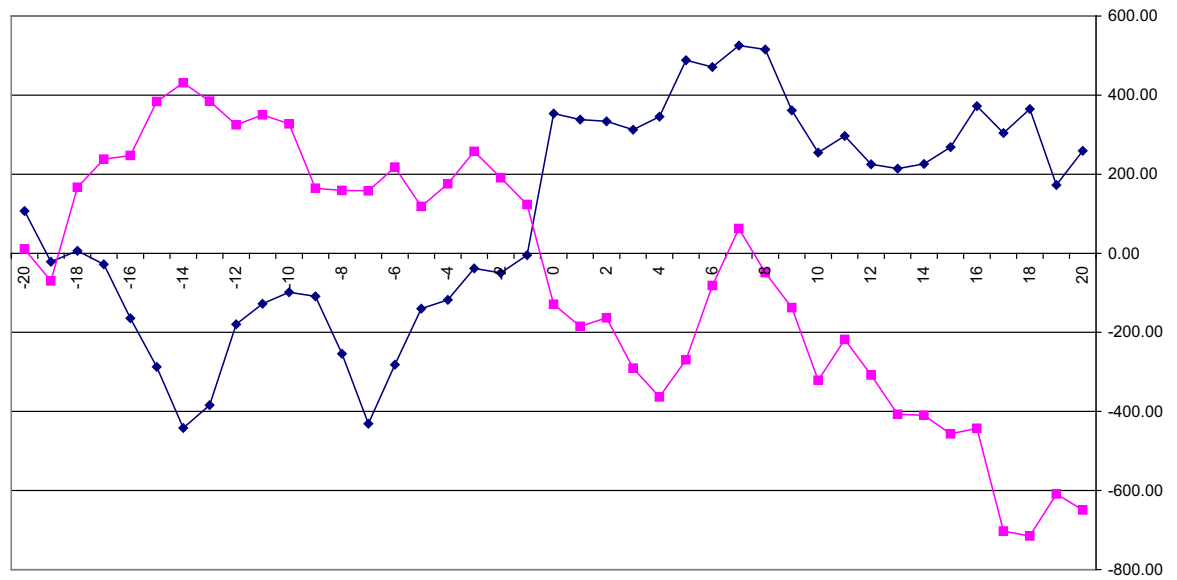

good news $\rightarrow$ - bad news

Fig. 7 Plot of proxy of cumulative abnormal returns for the constant mean model averaged for 12 companies. The proxy for the abnormal return is $\left(K_{\mathrm{it}}-83.5\right)$. The horizontal axis represents the event window, with date 0 as the event time. The vertical axis represents the proxy for the cumulative abnormal return for this period

results. After the event the signs of the cumulative abnormal returns change to negative, although the timing of this change is different for different stocks.

For Chinese and Russian companies, the $t$ test shows some surprising outcomes which are difficult to explain by the changes in the oil prices. For example, Sinopek's stocks have significant abnormal returns both for the 'good news' and 'bad news'. However, the cumulative abnormal return of 'positive oil price shock' is negative, while for the 'negative oil price shock' the sign of the cumulative abnormal return is positive. According to the $t$ test, for the rest of the stocks the event date does not have any impact.

\subsection{The nonparametric rank test}

To support the $t$ test we use nonparametric rank test. The size of the estimation window $W_{\text {est }}=126$ (half of the working year) and the event window $W_{\text {event }}=41$ (one working month before and after the event). The average rank is $1 / 2\left(W_{\text {est }}+W_{\text {event }}\right)=83.5$.

The proxy of the cumulative abnormal returns in the case of the constant mean model has a movement similar to the actual abnormal returns for portfolio of companies (Figs. 7, 8). We also should point out here that the rank test is conducted without cumulating proxy of the abnormal returns. The proxy for the abnormal return for the event date, in case of the constant mean model, is equal to 358.3, and the variance is 26.6 for the 'positive oil price shock.' The rank test for day zero, $\tau=0$, is 13.5 . The cumulative abnormal return is -252.9 , and the standard deviation is 27.4 for the 'negative oil price shock.' The rank test statistic in the case of 'bad news' is -9.2. Another significant negative abnormal return is observed 9 days before the event. The 


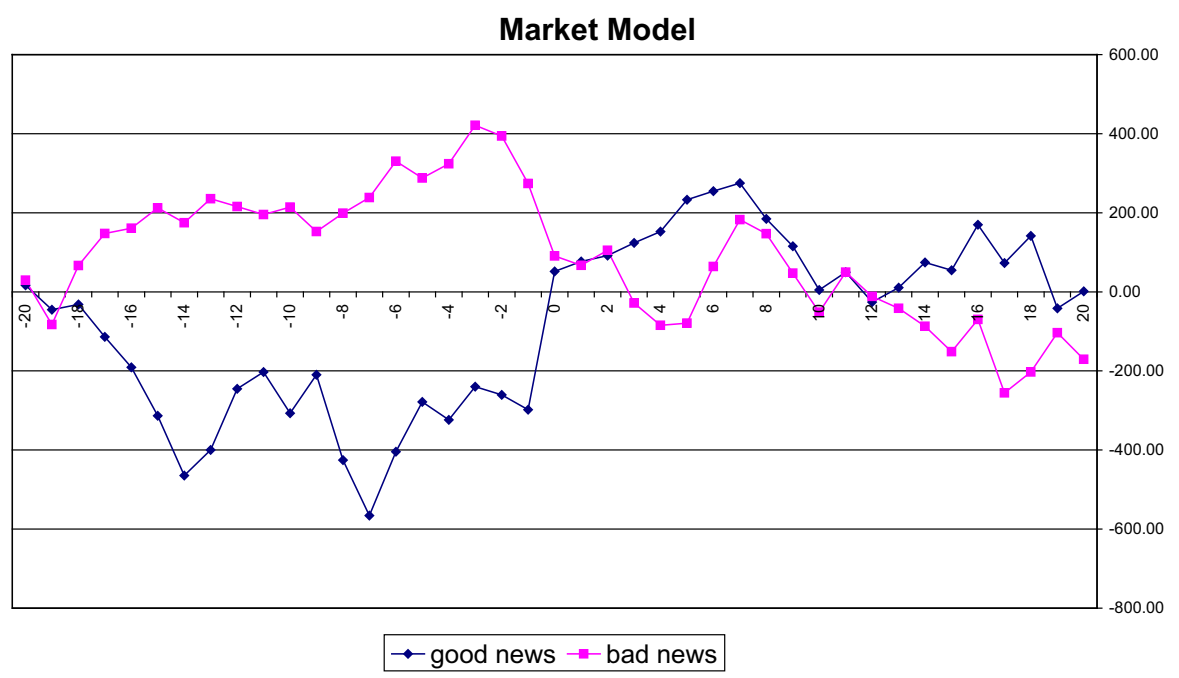

Fig. 8 Plot of proxy of cumulative abnormal returns for the market model averaged for 12 companies. The proxy for the abnormal return is $\left(K_{\mathrm{it}}-83.5\right)$. The horizontal axis represents the event window, with date 0 as the event time. The vertical axis represents the proxy for the cumulative abnormal return for this period

rank test statistic for that day is -6.1 . Interestingly, despite negative oil price shock you can also observe positive abnormal returns. Significant positive abnormal returns are observed on the 15th and 18th days before the event. The abnormal returns for these days are 136.2 and 236.4. The rank test statistic is equal to 5.1 for the day -15 , and it is equal to 8.1 for the day -18 .

For the rank test based on the market model, the proxies for the abnormal returns are 350.0 and -183.3 for the 'positive oil price shock' and 'negative oil price shock', respectively. The rank test statistics are 13.3 and -6.1 , respectively, and the null hypothesis that the event has no impact is strongly rejected. For the 'positive oil price shock', there is a significant level of negative abnormal return 2 weeks prior to the event date. The rank test statistics are -5.0 and 5.3 for the 14 th and 12 th day before the event, respectively. Significant negative abnormal returns are also observed on the 8th and 7th days before the event. However, on the 6th day the sign of the abnormal return changes to a positive one. The rank tests for those days are $-7.9,-5.3$ and 6.0, respectively. The 'negative oil price shock' has a positive abnormal return 18 days before the event and the rank test is 5.1 .

The tests undertaken for individual companies also show mixed results. The event has a considerable effect on Western companies, but in the case of Russian and Chinese oil companies, the changes in oil prices do not change the abnormal return significantly or, even, have an opposite effect.

Compared with the parametric test, the rank test indicates strong significance of abnormal returns for all Western stocks. In addition, the rank test shows high negative abnormal return approximately 2 weeks before the event. However, a week before the event there are significant positive abnormal returns for most of the securities. 
These are particularly noticeable with stocks of Chevron and Exxon Mobil. Another significant date is 9 days after the event. The rank test detects considerable negative abnormal returns on that date.

The 'negative oil price shock' also affects the share prices. The lowest value of the rank test statistic is observed for the stocks of Royal Dutch Shell, and the highest value is observed for the shares of Exxon Mobil. Yet again, the rank test indicates statistically significant positive abnormal returns 15 days before the event. The rank test results from the market model are consistent with those from the constant mean model. It indicates significant abnormal returns at the event date and significant positive abnormal returns 15 days before the event.

The picture is not clear for securities of Russian and Chinese companies. Overall, the changes in oil prices seem to have some effect on the share prices. However, in comparison with the Western companies, it is negligible. For instance, "positive oil price shock' is statistically significant for the shares of following companies: Lukoil, Gazprom, Surgutneftegaz and Petrochina. Significance for the "negative oil price shock' is observed for the stocks of Petrochina and China Petroleum and Chemicals. Despite this, the level of significance is much lower than those observed for the stocks of the Western companies. Interestingly, China Petroleum and Chemicals' shares have significant negative abnormal return 15 days before the event for the 'positive oil price shock'. While at the same date you can observe positive abnormal returns for most of the securities of the Western companies.

Finally, the nonparametric rank test shows that overall the abnormal returns of oil companies' shares for the analysed period are affected by oil price changes. In addition, there are significant abnormal returns before and after the event. The results obtained under the constant mean and the market models do not greatly differ. While the nonparametric rank test strongly indicates the existence of abnormal returns, the parametric test rejects the possibility of abnormal return. Bartholdy et al. (2007) point out that in some instances the tests may give different results. In such situations, the nonparametric test is more reliable in detecting the abnormal return. Thus, taking into account the results obtained by the nonparametric rank test, it is possible to say that oil price changes affect the shares of Western oil companies. However, the impact on Chinese and Russian companies is weak.

The analysis of individual companies showed that the reactions to the oil price news of shares of emerging and Western oil companies are different. For instance, the abnormal returns of most Western companies are negative, irrespective of news. The exceptions are Exxon Mobil and, to some extent, Chevron and Eni. In contrast, the investments into Russian and Chinese oil companies generate positive abnormal returns regardless of the type of news. A possible explanation of this result is that the oil companies are considered as politically strategic companies in China and Russia, and in many instances prone to political influences.

\section{Supplementary analysis}

This section gives a brief overview of the results of supplementary analysis on oil companies' shares. For the sake of brevity, we use only the market model. As robustness 


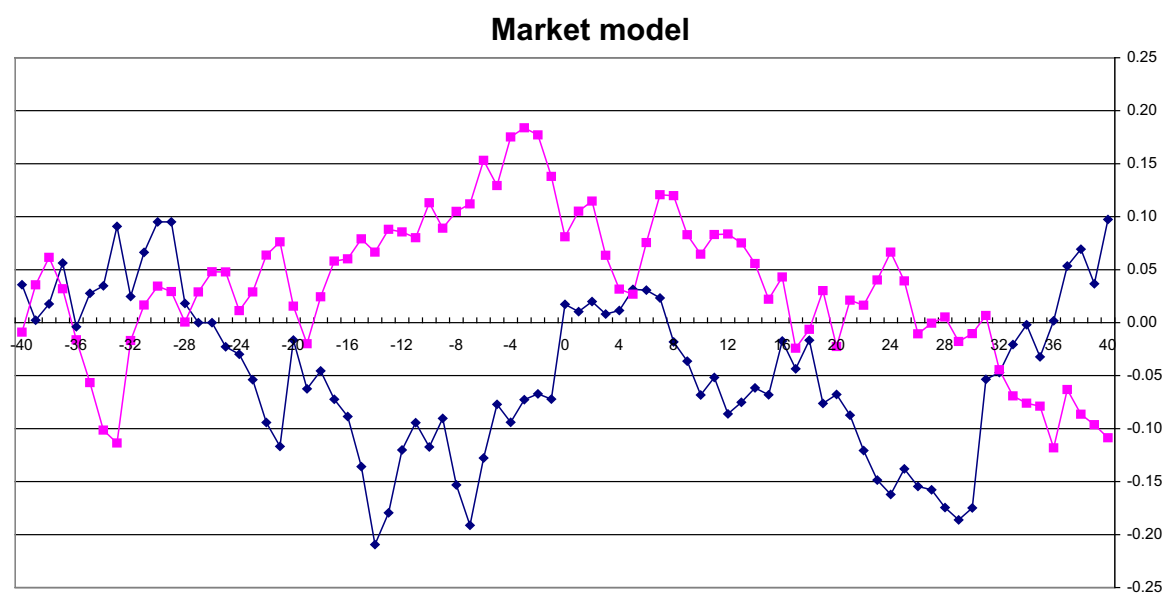

- good news $\rightarrow-$ bad news

Fig. 9 Plot of cumulative abnormal returns for the market model averaged for 12 companies. The horizontal axis represents the event window, with date 0 as the event time. The vertical axis represents the cumulative abnormal returns for this period

checks, we widened the event window to 81 days and computed abnormal returns for crude oil only with event window of 81 days. We increased the event window in order to identify whether our results will change if we increase the event window.

The most striking result from the analysis with a wider event window is that the pattern for the "good news" in the case of the cumulative abnormal returns and proxy of cumulative abnormal returns are noticeably different. There is a significant divergence in cumulative abnormal returns for positive news at the end of the analysed period. The comparative plots are given in Figs. 9 and 10.

Dynamics of oil returns The next plots (Figs. 11,12) represent the cumulative abnormal returns for crude oil and the proxy of cumulative abnormal returns for crude oil. If the trend of oil returns and the patterns of oil companies' shares (Figs. 8, 9) are similar, this would imply that possibly oil returns are the main factors influencing the companies' shares. As can be seen from the graphs, in general, the oil returns determine the performance of the oil companies' shares. This is in line with the finding of this paper.

\section{Conclusion}

This analysis aims to fill a gap in the empirical research of event studies of oil companies. It focus on the question of whether changes in oil prices have an impact on share prices of oil companies in emerging economies and Western oil companies. The nonparametric rank test results reveal considerable abnormal returns for oil companies. However, the tests also show a discrepancy among the companies from different economic areas. For example, while oil price changes affect stock prices of American and European oil companies as expected, the most atypical behaviour is observed for 


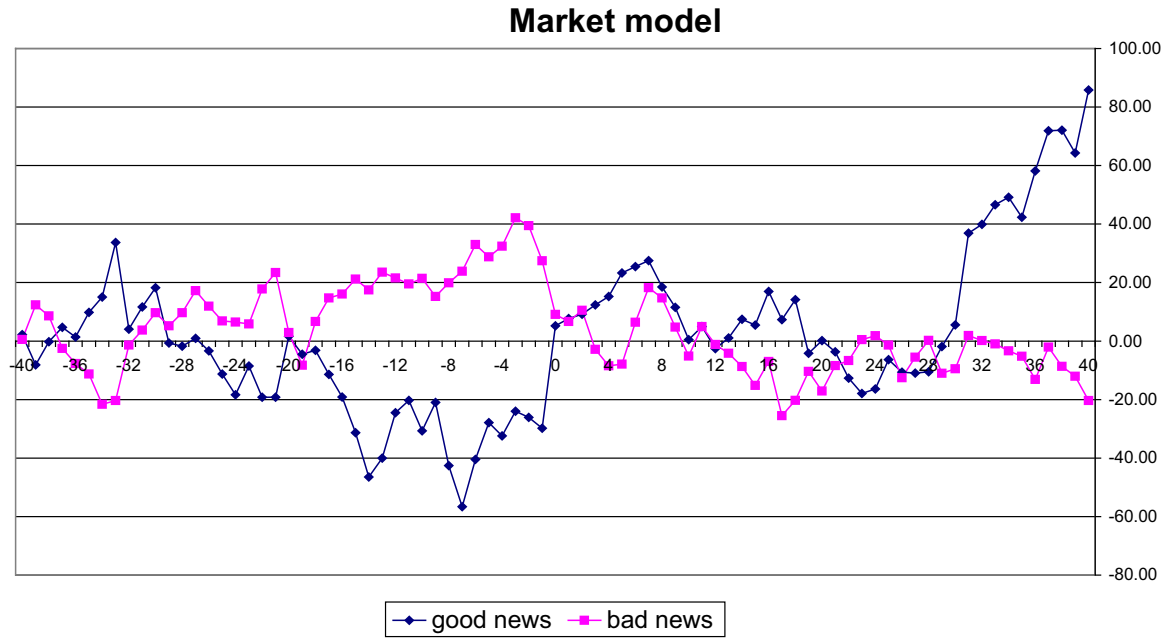

Fig. 10 Plot of proxy of cumulative of abnormal returns for the market model averaged for 12 companies. The proxy for the abnormal return is $\left(K_{\mathrm{it}}-83.5\right)$. The horizontal axis represents the event window, with date 0 as the event time. The vertical axis represents the proxy for the cumulative abnormal return for this period (rescaled)

\section{Market model}

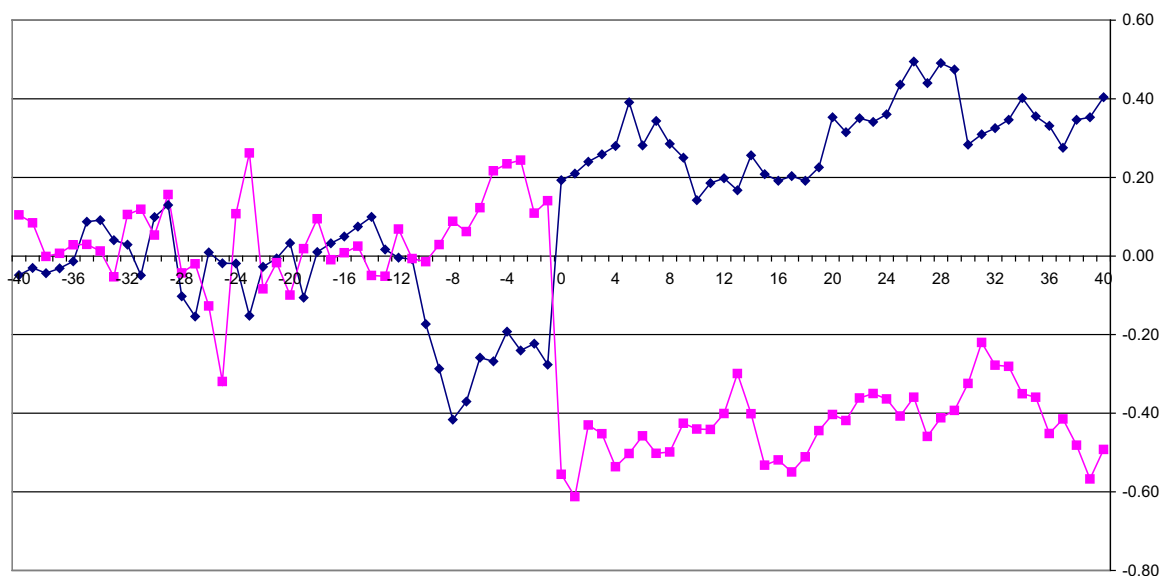

$\rightarrow$ good news $\rightarrow$ - bad news

Fig. 11 Plot of cumulative abnormal returns of crude oil, (the market model used). The horizontal axis represents the event window, with date 0 as the event time. The vertical axis represents the cumulative abnormal returns for this period

the securities of Chinese and Russian companies. The possible explanation of this result is that the oil companies considered as strategic companies in China and Russia and in many instances prone to political influences. Further research is required to explain why the Russian and Chinese oil companies behave differently. Potential 


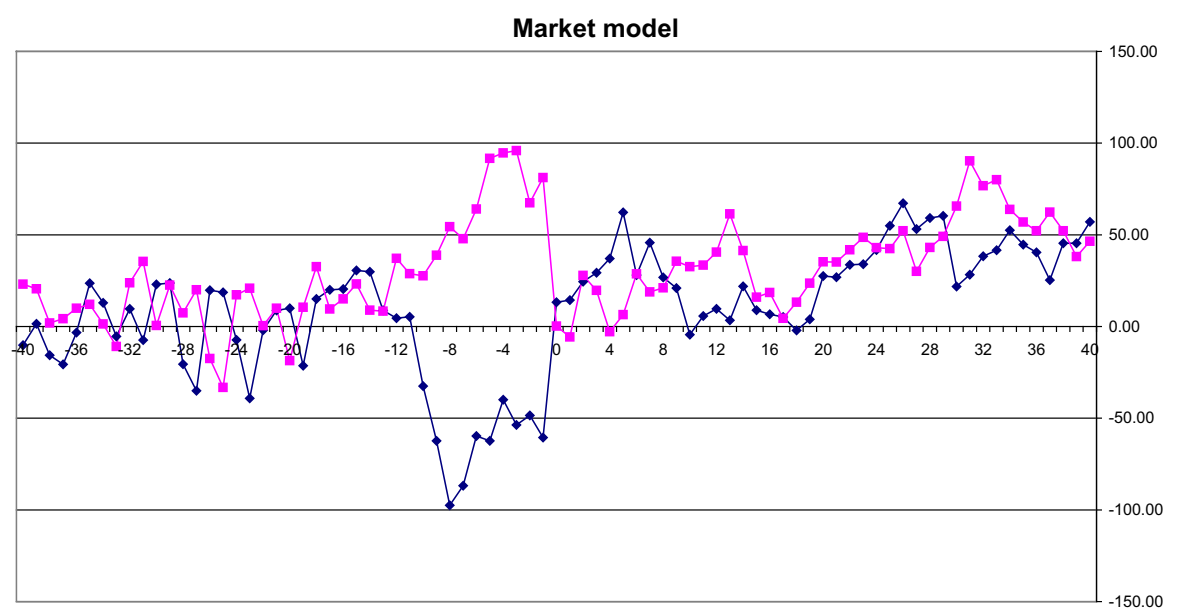

good news $\rightarrow-$ bad news

Fig. 12 Plot of proxy of cumulative abnormal returns of crude oil, (the market model used). The proxy for the abnormal return is $\left(K_{\mathrm{it}}-83.5\right)$. The horizontal axis represents the event window, with date 0 as the event time. The vertical axis represents the proxy for the cumulative abnormal return for this period (rescaled)

causes of such performances of the shares are inside information, political influences and corruption.

Open Access This article is distributed under the terms of the Creative Commons Attribution 4.0 International License (http://creativecommons.org/licenses/by/4.0/), which permits unrestricted use, distribution, and reproduction in any medium, provided you give appropriate credit to the original author(s) and the source, provide a link to the Creative Commons license, and indicate if changes were made.

\section{References}

Baillie R, Bollerslev T (1989) The message in daily exchange rates: a conditional-variance tale. J Bus Econ Stat 7:297-305

Ball C, Taurus W (1988) Investigating security-price performance in the presence of event date uncertainty. J Financ Econ 22:123-153

Bartholdy J, Olson D, Peare P (2007) Conducting event studies on a small stock exchange. Eur J Finance 13:227-252

Brooks C (1996) Testing for non-linearity in daily sterling exchange rates. Appl Financ Econ 6:307-317

Brown S, Warner J (1980) Measuring security price performance. J Financ Econ 8:205-258

Brown S, Warner J (1985) Using daily stock returns: the case of event studies. J Financ Econ 14:3-31

Corhay A, Rad A (1996) Conditional heteroskedasticity adjusted market model and an event study. Q Rev Econ Finance 36:529-538

Corrado C (1989) A nonparametric test for abnormal security-price performance in event studies. J Financ Econ 23:385-395

Corrado C, Zivney T (1992) The specification and power of the sign test in event study hypothesis tests using daily stock returns. J Financ Quant Anal 27:465-478

Cowan A (1992) Nonparametric event study tests. Rev Quant Finance Account 2:343-358

Cowan A, Sergeant A (1996) Trading frequency and event study test specification. J Bank Finance 20:17311757 
de Jong F, Kemna A, Kloek A (1992) A contribution to event study methodology with an application to the Dutch stock market. J Bank Finance 16:11-36

Díaz A, Jareno F (2013) Inflation news and stock returns: market direction and flow-through ability. Empir Econ 44:775-798

Dyckman T, Philbrick D, Stephean J (1984) A comparison of event study methodologies using daily stock returns: a simulation approach. J Account Res 22:1-30

Higgins E, Peterson D (1998) The power of one and two sample t-statistics given event-ainduced variance increases and nonnormal stock returns: a comparative study. Q J Bus Econ 37:27-49

Hsieh D (1988) The statistical properties of daily foreign exchange rates: 1974-1983. J Int Econ 24:129-145

Jain P (1986) Analyses of the distribution of security market model prediction errors for daily returns data. J Account Res 24:76-96

Kenjegaliev A, Duygun M, Mamedshakhova D (2016) Do rating grades convey important information: German evidence? Econ Model 53:334-344

Kritzman M (1994) What practitioners need to know... about event studies. Financ Anal J 50:17-20

Liebman B, Tomlin K (2015) World Trade Organization sanctions, implementation, and retaliation. Empir Econ 48:715-7445

MacKinlay A (1997) Event studies in economics and finance. J Econ Lit 35:13-39

McWilliams A, Siegel D (1997) Event studies in management research: theoretical and empirical issues. Acad Manage J 40:626-657 